\title{
KINETICS OF THE REVERSIBLE PHOTOAQUATION OF THE OCTACYANOMOLYBDATE(IV) ION*
}

\author{
VILMOS GÁSPÁR and MIHÁLY T. BECK† \\ Department of Physical Chemistry, Institute of Chemistry, Kossuth Lajos University, \\ Debrecen, P.O. Box 7, H-4010, Hungary
}

(Received 4 June 1986; accepted 23 June 1986)

\begin{abstract}
The kinetics of the photoaquation of the octacyanomolybdate(IV) ion in aqueous solution were studied by potentiometric and spectrophotometric methods. In an alkaline medium a simple scheme analogous to the photoaquation of the hexacyanoferrate(II) ion describes the process. The values of the constants of the kinetic equation are: $\Phi=1.0$, $k_{8}=(6.55 \pm 0.8) \times 10^{-9} \mathrm{~s}^{-1}$, and $k_{-8}=(7.88 \pm 0.5) \times 10^{-2} \mathrm{~mol}^{-1} \mathrm{dm}^{3} \mathrm{~s}^{-1}(\mathrm{pH}=10.5)$. The reversibility of the photoaquation is also explained by the scheme. A simultaneous measurement of free cyanide ion concentration and the absorbance at $512 \mathrm{~nm}$ shows that the red coloured transition product is a heptacyano complex.
\end{abstract}

The kinetics and mechanism of the photoaquation of different cyano complexes have been intensively studied for a long time. ${ }^{1}$ Nevertheless, the reversible photoaquation of hexacyanoferrate(II) and octacyanomolybdate(IV) ions remained unsolved. In an earlier paper we dealt with the kinetics of the photoaquation of the hexacyanoferrate(II) ion. ${ }^{2}$ It was shown that a simple scheme (see Fig. 3 in Ref. 2) explains all the experimental observations. The success of those experiments is due to the application of a cyanide-selective electrode. This sensor can sensitively monitor both the thermal reactions and the photoreactions without perturbing the system, even if the conversions are very small. Since there are many similarities in the photochemistry of the two cyano complexes, we have tried to investigate the photoaquation of the octacyanomolybdate(IV) ion in an alkaline medium by applying the same experimental and computational

*Dedicated to Professor Viktor Gutmann on the occasion of his 65th birthday.

†Author to whom correspondence should be addressed. methods as in the case of the hexacyanoferrate(II) ion. $^{2}$

The aqueous solution of the complex ion is stable in the dark. The rate constant of its thermal aquation reaction was determined by Wilson et al. ${ }^{3}$ Its value is $8.5 \times 10^{-8} \mathrm{~s}^{-1}$. It is well known ${ }^{1}$ that on illumination by sunlight or $365-\mathrm{nm}$ monochromatic light the yellow coloured aqueous solution of the complex turns to red and hydrogen cyanide is formed simultaneously. By interrupting the illumination, the solution turns back to its original yellow. The photoreaction is reversible. If, however, the irradiation time is longer, the transient red colour disappears and the solution turns irreversibly green and finally blue. Formation of a blue precipitate can also be observed at a high concentration of the complex.

Mitra and Mohan ${ }^{4}$ isolated a yellow complex as a potassium salt by addition of a calculated amount of $\mathrm{KOH}$ to the red solution. The composition of this yellow complex was $\mathrm{K}_{4} \mathrm{MO}(\mathrm{CN})_{7}(\mathrm{OH})$. Their experiments suggest that the blue product is formed by photolysis of this complex ion, rather than, as previously supposed, by a series of thermal reactions. A careful investigation of this blue product showed that it should be a mixture of different 
species. Their results can be summarized by the following scheme:

$$
\text { Primary product } \stackrel{+\mathrm{OH}^{-}}{\longrightarrow}\left[\mathrm{Mo}(\mathrm{CN})_{7} \mathrm{OH}\right]^{4-}
$$$$
\text { (red, } \lambda_{\max }=512 \mathrm{~nm} \text { ) (yellow) }
$$

$$
\begin{aligned}
& {\left[\mathrm{Mo}(\mathrm{OH})_{2}(\mathrm{CN})_{4}\right]^{2-} \underset{+\mathrm{H}_{2} \mathrm{O}}{\stackrel{+\mathrm{OH}^{-}}{\rightleftarrows}}\left[\mathrm{MoO}(\mathrm{OH})(\mathrm{CN})_{4}\right]^{3-\underset{\mathrm{H}_{2} \mathrm{O}}{\stackrel{+\mathrm{OH}^{-}}{\rightleftarrows}}\left[\mathrm{MoO}_{2}(\mathrm{CN})_{4}\right]^{4-}}} \\
& \text { (blue, } \left.\lambda_{\max }=618 \mathrm{~nm}\right) \quad\left(\text { blue }, \lambda_{\max }=595 \mathrm{~nm}\right) \quad\left(\mathrm{red}, \lambda_{\max }=515 \mathrm{~nm}\right)
\end{aligned}
$$
the controversy.

Surprisingly, the composition of the primary product is still a subject of controversy in the literature. A number of investigations ${ }^{5-8}$ support the following simple reaction (A) as the primary process:

$$
\begin{aligned}
& {\left[\mathrm{Mo}(\mathrm{CN})_{8}\right]^{4-} \underset{h v(\mathrm{LF})_{1}+\mathrm{H}_{2} \mathrm{O}}{\rightleftarrows}\left[\mathrm{Mo}(\mathrm{CN})_{7}\left(\mathrm{H}_{2} \mathrm{O}\right)\right]^{3-}+} \\
& \text { (yellow) } \mathrm{CN}^{-} \text {. (red) }
\end{aligned}
$$

Jakob et al. ${ }^{9}$ proposed reaction (B) that results in an increase in the coordination number:

$$
\left[\mathrm{Mo}(\mathrm{CN})_{8}\right)^{4-} \underset{h v(L \mathrm{LF})_{1}+2 \mathrm{H}_{2} \mathrm{O}}{\rightleftarrows}\left[\mathrm{Mo}(\mathrm{CN})_{8}\left(\mathrm{H}_{2} \mathrm{O}\right)_{2}\right]^{4-}
$$

Reaction (C) was suggested by different authors $^{10,11}$ according to spectrophotometric investigations:

$$
\left[\mathrm{Mo}(\mathrm{CN})_{8}\right]^{4-} \underset{\mathrm{CN}^{-}}{\stackrel{h v(\mathrm{LF})_{,}+\mathrm{OH}^{-}}{\rightleftarrows}\left[\mathrm{Mo}(\mathrm{CN})_{7}(\mathrm{OH})\right]^{3-}+}
$$

The conductometric and $\mathrm{pH}$ titration curves ${ }^{12}$ of the photolysed solutions of octacyanomolybdic acid corresponding to the stage of maximum optical density at $512 \mathrm{~nm}$ showed a sharp minimum and an inflexion, respectively, at 4 equivalents of $\mathrm{KOH}$ per mole of the complex. First the three strong $\mathrm{H}^{+}$ ions were neutralized and then in a slow reaction 1 equivalent of the base was consumed. This latest process was attributed to a ligand exchange reaction, in which the coordinated water molecule of the product of reaction (A) was replaced by an $\mathrm{OH}^{-}$ ion. According to these observations, reactions (B) and $(C)$ cannot be taken into account as the main photoreactions.

Our esperimental set-up allows us to determine simultaneously the free cyanide ion concentration and the optical density at the characteristic wavelength of the red species. Therefore we can perform a direct experimental investigation of the primary
We hoped that an exact kinetic investigation of the photoaquation by our method ${ }^{2}$ would result in an accurate value of the quantum yield, since rather different values were determined earlier by different methods (Table 1.)

\section{EXPERIMENTAL}

Potassium octacyanomolybdate(IV) dihydrate was obtained by the method of Van de Poel and Neumann. ${ }^{14}$ The yellow crystals were recrystallized 4 or 5 times from ethanol solutions. Purity was controlled by a spectrophotometric method $\left(\varepsilon=15,540 \mathrm{~mol}^{-1} \mathrm{dm}^{3} \mathrm{~cm}^{-1}\right.$ at $\left.240 \mathrm{~nm}\right)$.

\section{(A) Investigation of the stoichiometry of the primary photoreaction}

$120 \mathrm{~cm}^{3}$ of $2.5 \times 10^{-3} \mathrm{~mol} \mathrm{dm}^{-3}$ potassium octacyanomolybdate(IV) solution was put into a $150 \mathrm{~cm}^{3}$ beaker. The $\mathrm{pH}$ of the solution was adjusted to 10.3 by adding a few drops of $1.0 \mathrm{M}$

Table 1. Quantum yield $(\Phi)$ of the photoaquation of the octacyanomolybdate(IV) ion on the exposure to $365-\mathrm{nm}$ light

\begin{tabular}{lcc}
\hline \multicolumn{1}{c}{ Method } & $\Phi$ & Reference \\
\hline $\begin{array}{l}\text { Determination of } \mathrm{OH}^{-} \\
\text {production, initial } \mathrm{pH}=6-7\end{array}$ & $0.8-0.9$ & 6 \\
$\begin{array}{l}\text { Determination of the initial rate } \\
\text { of the decrease in }\end{array}$ & & \\
{$\left[\mathrm{Mo}(\mathrm{CN})_{8}^{4}\right]^{4-}$} \\
concentration by \\
spectrophotometric method in \\
$\begin{array}{l}\text { 0.1 M KOH solution } \\
\text { Determination of cyanide ion } \\
\text { production by } \\
\text { spectrophotometric } \\
\text { method, pH = 8-12 in borate } \\
\text { buffer }\end{array}$ \\
\hline
\end{tabular}


carbonate-free sodium hydroxide solution. The solution was kept in the dark and under an argon atmospherc for at least $30 \mathrm{~min}$. The free cyanide concentration was monitored potentiometrically by using an OP-711-D-I ion-selective electrode and a Radiometer Type K401 saturated calomel electrode with an OP-205 Radelkis mV-meter. The $\mathrm{pH}$ of the solution was measured by a combined glass electrode (GK 301 B Radiometer) and a PHM-51 Radiometer $\mathrm{mV}$-meter. A Hitachi-Perkin-Elmer 139 single-beam spectrophotometer was used for determination of the absorbance of the red product at $512 \mathrm{~nm}$. The optical length of the flow-cell was $0.51 \mathrm{~cm}$. The solution was stirred with a magnetic stirrer.

After reaching an equilibrium state in the dark, the solution was irradiated by sunlight. (Although sunlight is not monochromatic, its intensity is much more higher than that of the lamp used in our standard photochemical experiments. Therefore, on illumination by sunlight the red state was reached within a few minutes.)

The side of the beaker opposite to the direction of the irradiation was covered with an aluminium foil to maintain nearly the same intensity of irradiation in the whole volume of the solution.

\section{(B) Kinetics of the photoaquation in an alkaline medium}

A detailed description of the photochemical device is given in our earlier paper. ${ }^{2}$ In these experiments, however, the light source was a TUNGSRAM PRK-2 medium-pressure mercury lamp. The constant intensity of irradiation was measured by the ferrioxalate method. ${ }^{15}$ It amounts to $2.1 \pm 0.1 \times 10^{-10} \mathrm{~mol}$ of photons $(365 \mathrm{~nm}) \mathrm{cm}^{-2}$ s. For monitoring the reaction, the same electrodes and $\mathrm{mV}$-meters were used as described in part (A) of this section.

\section{RESULTS AND DISCUSSION}

Figure 1 shows the simultaneous changes in the absorbance at $512 \mathrm{~nm}$ and the free cyanide concentration on exposure to sunlight. The cyanide ion concentration increases monotonically to a final value that corresponds to $1.8 \mathrm{~mol}$ of free cyanide

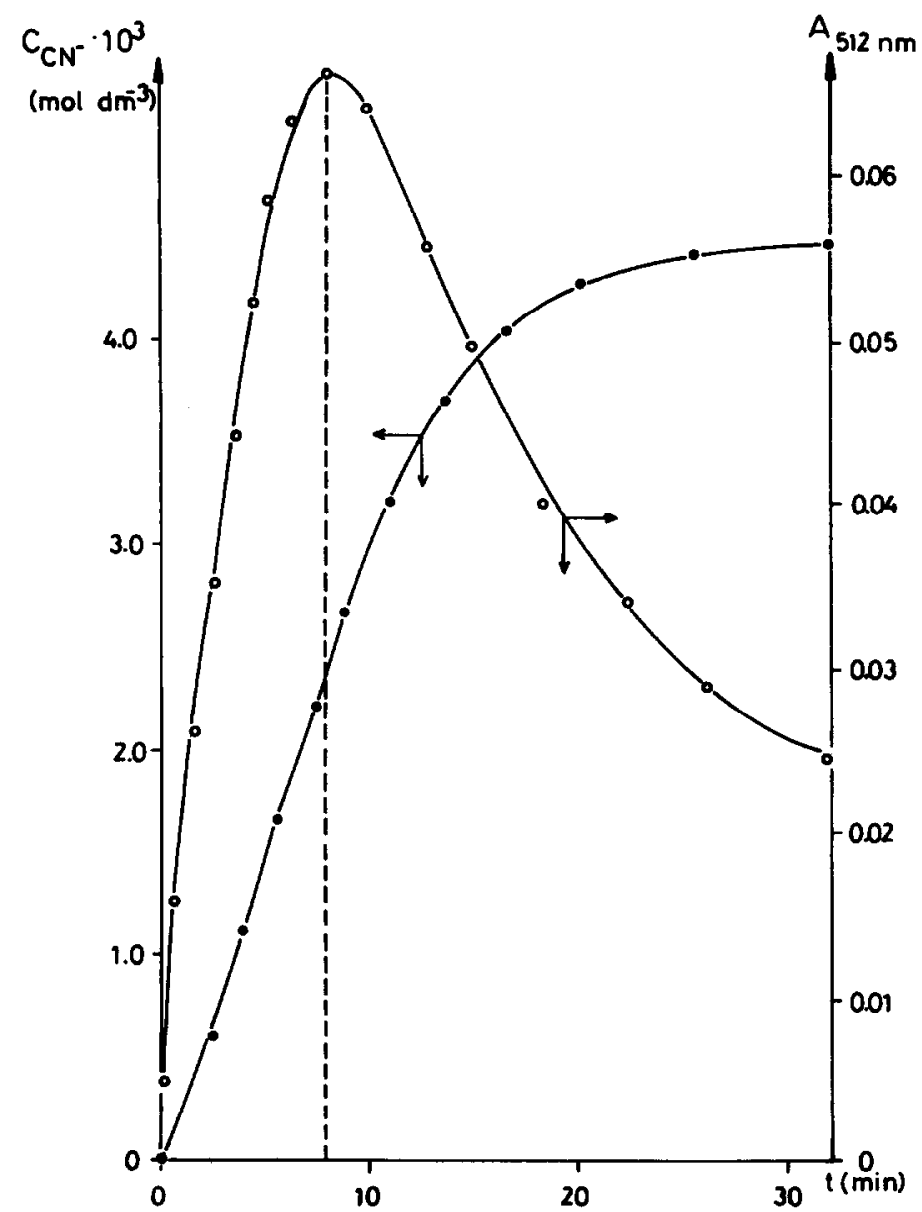

Fig. 1. Simultaneous change in the free cyanide ion concentration $(0)$ and absorbance $(0)$ at $512 \mathrm{~nm}$ on exposure to sunlight. $[\mathrm{Mo}(\mathrm{CN})]_{0}^{4-}=2.5 \times 10^{-3} \mathrm{~mol} \mathrm{dm}^{-3}$. 
ion released by $1 \mathrm{~mol}$ of the initial complex ion. The absorbance changes according to a maximum curve. At the maximum value the free cyanide ion concentration is $2.35 \times 10^{-3} \mathrm{~mol} \mathrm{dm}^{-3}$. Since in a strongly alkaline solution the amount of hydrogen cyanide formed can be neglected, the kinetic mean coordination number $\left(\bar{n}_{t}\right)$ can be calculated by the following equation:

$$
\bar{n}_{t}=\frac{T_{\mathrm{CN}}-\left[\mathrm{CN}^{-}\right]_{t}}{\mathrm{~T}_{\mathrm{Mo}}}
$$

where $T_{\mathrm{CN}}$ and $T_{\mathrm{Mo}}$ are the analytical concentrations, and $\left[\mathrm{CN}^{-}\right]_{t}$ is the actual concentration of the free cyanide ion. At the maximum value of the absorbance $\bar{n}_{\max }=7.06$. This value is in good agreement with the stoichiometry proposed by reaction $(A)$.

The roughly estimated molar absorbance of the red species is about $50 \mathrm{~mol}^{-1} \mathrm{dm}^{3} \mathrm{~cm}^{-1}$. Its magnitude is consistent with the fact that the ligand-field transitions are symmetry-forbidden.

The small decrease $(0.1-0.2 \mathrm{pH}$ units) in $\mathrm{pH}$ during the irradiation confirms the reaction scheme of Mitra and Mohan. ${ }^{4}$

When the intensity of the irradiating light is small as in our kinetic experiments and the time of illumination is not too long, the reaction system remains in the so-called reversible stage. Figure 2 shows a few periods of the alternating increase and decrease in the free cyanide concentration in the subsequent periods of illumination and darkness.

This behaviour of the system can be qualitatively described by scheme (D), neglecting the decomposition and the ligand exchange reaction of the red species: the recombination and decomposition of the excited complex ion, respectively. $k_{8}$ and $k_{-8}$ are the rate constants of the thermal reactions. $K_{d}$ is the dissociation constant of hydrogen cyanide.

Introducing the quantum yield $\Phi$ $\left[=k_{f} /\left(k_{f}+k_{r}\right)\right]$ and applying the steady-state approximation for the concentration of the excited complex ion, the following rate equation can be derived:

$$
\begin{aligned}
- & \frac{\mathrm{d}\left[\mathrm{Mo}(\mathrm{CN})_{8}\right]^{4-}}{\mathrm{d} t}=\frac{\mathrm{d}\left[\mathrm{Mo}(\mathrm{CN})_{7}\left(\mathrm{H}_{2} \mathrm{O}\right)\right]^{3-}}{\mathrm{d} t} \\
= & \Phi I_{c}+k_{8}\left[\mathrm{Mo}(\mathrm{CN})_{8}\right]^{4-} \\
& -k_{-8}\left[\mathrm{Mo}(\mathrm{CN})_{7}\left(\mathrm{H}_{2} \mathrm{O}\right)^{3-}\right]\left[\mathrm{CN}^{-}\right] .
\end{aligned}
$$

Taking into account that the total amount of cyanide released by the complex ion always equals the concentration of the heptacyano complex ion, the concentration of hydrogen cyanide, cyanide and hydroxide ions can be calculated as the components of an acid-base equilibrium system. The exact values of the constants of the kinetic equation were calculated by a least-squares method from the linear algebraic system of the equations given for the parameters. The calculation of the kinetic curves (full lines in Fig. 2) was based on the required combination of the fourth-order Runge-Kutta and Newton-Raphson numerical methods. The values of the constants are: $\Phi=1.0$, $k_{8}=(6.55 \pm 0.8) \times 10^{-9} \mathrm{~s}^{-1}, \quad$ and $k_{-8}=(7.88$ $\pm 0.5) \times 10^{-2} \mathrm{~mol}^{-1} \mathrm{dm}^{3} \mathrm{~s}^{-1}$. According to these data the photostationary $\left(A^{*}\right)$ and thermal-equilibrium $(A)$ values of free cyanide ion concentration can be calculated. As is shown by Fig. 2, the difference between these values is nearly one order

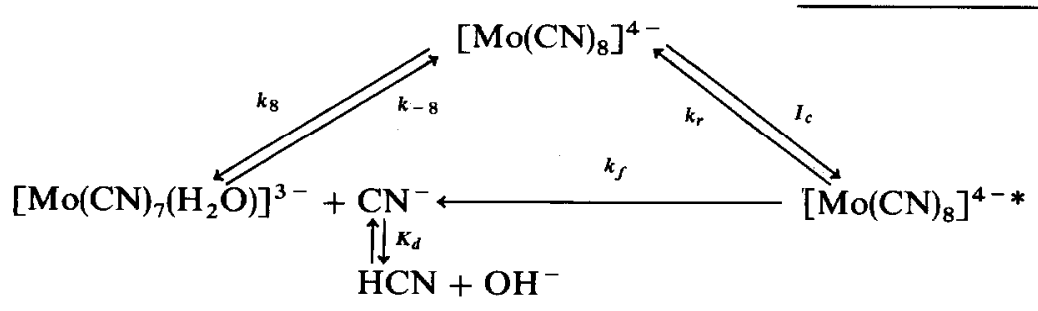

This scheme is completely analogous to the scheme applied for the description of the kinetics of the photoaquation of the hexacyanoferrate(II) ion in alkaline solution. (The water molecules are systematically omitted from the scheme.) $I_{c}$ is the average number of moles of photons $(365 \mathrm{~nm})$ absorbed by the complex ion per unit volume and unit time. In our experiments it amounts to $6.3 \times 10^{-8} \mathrm{~mol}$ of photons $\mathrm{dm}^{-3} \mathrm{~s}^{-1}$. $\left[\mathrm{Mo}(\mathrm{CN})_{8}\right]^{4-*}$ is the excited state of the complex ion. $k_{r}$ and $k_{f}$ are the first-order rate constants of of magnitude only. The reversibility of the photoaquation can be interpreted in the light of the two stable solutions, depending on the conditions.

Applying the definition of the $\bar{n}_{t}$, its change during the reaction can be easily calculated (see dashed line in Fig. 2). The conversions in both photoreactions and thermal rcactions are small (1.98 and $0.11 \%$, respectively). Nevertheless, these very small changes could be exactly determined because of the high sensitivity of the cyanide ion selective electrode. 


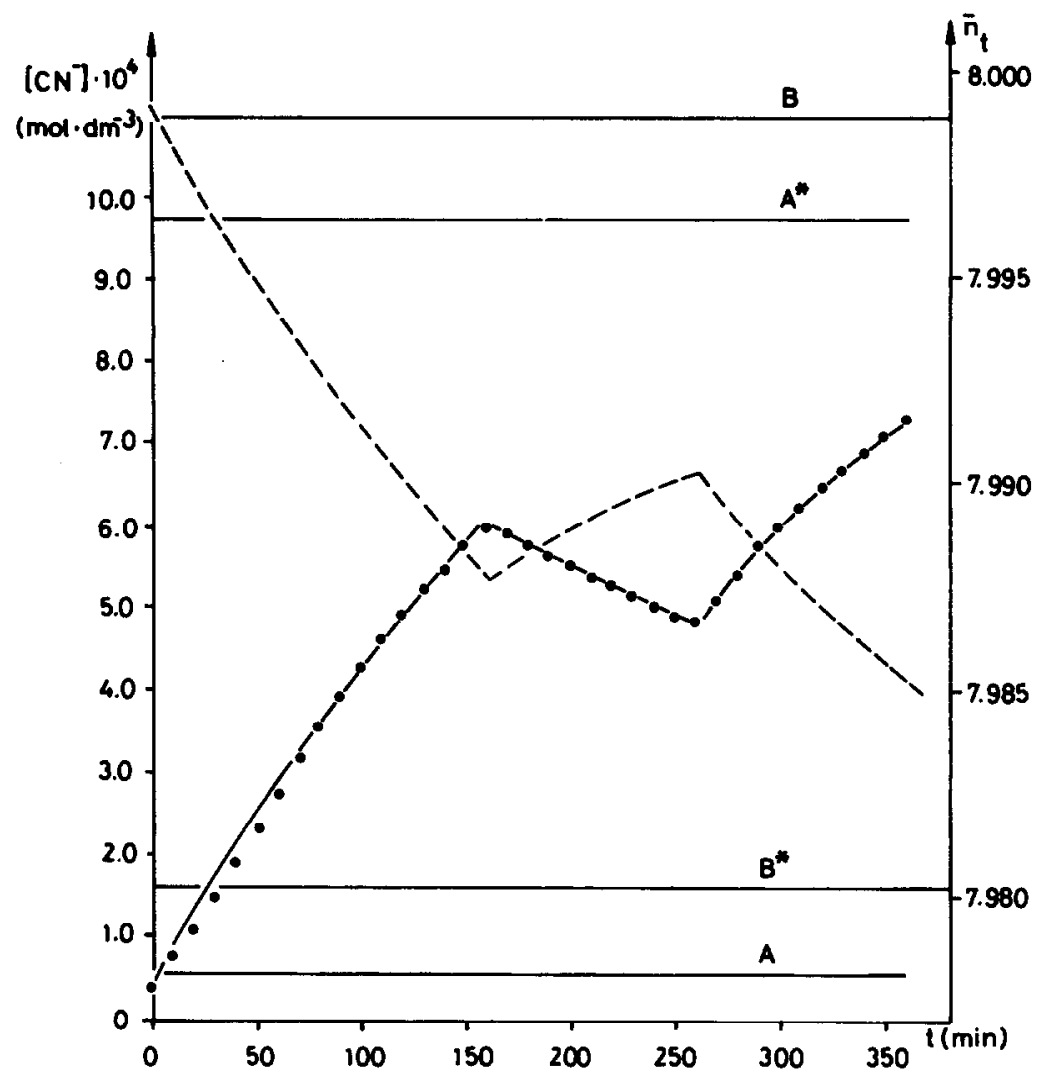

Fig. 2. Experimental ( $\odot$ ) and calculated (full line) changes in the free cyanide ion concentration in $5.0 \times 10^{-2} \mathrm{~mol} \mathrm{dm}^{-3}$ octacyanomolybdate(IV) solution at $\mathrm{pH}=10.5$. The order of periods is: illumination, darkness, illumination. Dashed line: calculated change in the kinetic mean coordination number $\left(\bar{n}_{t}\right) . A$ and $A^{*}$ are the thermal and photostationary values of the free cyanide ion concentration, respectively. $B$ and $B^{*}$ are the analogous values of the coordination number.

It follows from the kinetic data that the stability constant of the eighth complex $\left(K_{8}\right)\left(=k_{-8} / k_{8}\right)$ is $(1.2 \pm 0.1) \times 10^{7} \mathrm{~mol}^{-1} \mathrm{dm}^{3}$. Unfortunately, no reference data are available in the literature on the stability of the complex ion or on the stepwise complex formation reactions. Our result is consistent with the fact that the hexacyanoferrate(II) ion is more stable in alkaline solution and its $K_{6}$ value $^{2}$ is higher by a factor of 5 .

One should take into consideration that scheme (D) is correct only in the case of small conversions. For describing the complete photochemical decomposition of the octacyanomolybdate(IV) ion, scheme (D) should be simply extended by the reaction scheme of Mitra and Mohan. ${ }^{4}$

\section{REFERENCES}

1. V. Balzani and V. Carassiti, Photochemistry of Coordination Compounds. Academic Press, New York (1970).

2. V. Gáspár and M. T. Beck, Polyhedron 1983, 2, 378.
3. R. D. Wilson, V. S. Sastri and C. H. Langford, Can. J. Chem. 1971, 49, 679.

4. R. P. Mitra and H. Mohan, J. Inorg. Nucl. Chem. 1974, 36, 3739.

5. V. Carassiti and V. Balzani, Ann. Chim. (Rome) 1960, 50, 630 .

6. V. Balzani, M. Monfrin and L. Moggi, Inorg. Chem. $1969,8,47$.

7. A. W. Adamson, J. P. Welker and M. Volpe, J. Am. Chem. Soc. 1950, 72, 4030.

8. A. W. Adamson and J. J. Perummareddi, Inorg. Chem. 1965, 4, 247.

9. W. Jakob, A. Samotus and Z. Stasicka, Rocz. Chem. 1962, 36, 611; ibid. 1966, 40, 967; ibid. 1966, 40, 1383; Z. Naturforsch. 1966, 21B, 819.

10. V. Carassiti, A. M. Mavirangeli and V. Balzani, Arn. Chim. (Rome) 1960, 50, 790.

11. A. Samotus, Z. Stasicka, A. Dudek and L. Nadzeija, Rocz. Chem. 1971, 45, 299.

12. R. P. Mitra, B. K. Sharma and H. Mohan, Can. J. Chem. 1969, 47, 2317.

13. E. J. Bowen, J. Chem. Soc. 1935, 76.

14. J. Van de Poel and H. M. Neumann, Inorg. Synth. 1968, 11, 53.

15. C. G. Hatchard and C. A. Parker, Proc. R. Soc. London 1956, A235, 518. 